\title{
Idas y venidas: los nobles indígenas mesoamericanos antes y después de la Conquista Española
}

\author{
José Luis de RoJas \\ Departamento de Historia de América II (Antropología de América) \\ Universidad Complutense de Madrid \\ phempo@ghis.ucm.es
}

Recibido: 18 de enero de 2011

Aceptado: 14 de febrero de 2011

\section{RESUMEN}

Chance y Stark (2007) han propuesto las diferentes estrategias seguidas por los indígenas mesoamericanos antes y después de la Conquista española. En esa línea queremos presentar ahora un panorama de los cambios y continuidades que los nobles indígenas mesoamericanos tuvieron a partir de la llegada de los españoles. En él se contempla la identidad de muchas estrategias y los beneficios que los estudios sobre los señores prehispánicos obtienen de analizar los comportamientos coloniales y cómo podemos comprender a los señores coloniales conociendo a los prehispánicos.

Palabras clave: Nueva España, Mesoamérica, aztecas, nobles indígenas.

\section{Go In and Go Out: The Mesoamerican Indian Nobility Before and After the Spanish Conquest}

\begin{abstract}
Chance and Stark (2007) have proposed different strategies followed by the Mesoamerican Indians before and after the Spanish Conquest. In a similar way we want to present a view over the changes and continuities of the Mesoamerican Indian nobility since the arrival of the Spaniards. In this view we deal with the identity of a lot of strategies and the profits that the studies about prehispanic lords earn from the analysis of the colonial behaviour, and also how we can understand the colonial lords knowing better the prehispanic nobles.
\end{abstract}

Key words: New Spain, Mesoamerica, Aztecs, Indian nobility.

Para estudiar cualquier evolución es necesario conocer el punto de partida y el de llegada, pero también el proceso que conduce de uno a otro. Tanto la partida como la llegada no están dadas objetivamente, sino que son determinadas por los investigadores por razones diversas, entre las que se cuentan las tradiciones, las modas, los gustos y los intereses personales. Pero son variables dependientes y la elección de unos u otros puede ser determinante en el resultado final. Aún cuando seamos lo más precisos y objetivos posibles, un cambio en las premisas puede acarrear cambios en los resultados. Y como muy bien señaló Chalmers (1994: 17-23) los razonamientos lógicos pueden ser verdaderos, pero con premisas falsas, por lo que el resultado será también falso.

En el caso de la nobleza indígena de México hablamos de redes de poder y debemos preguntarnos qué es más importante para un individuo, su afiliación étnica, su filiación familiar o su status personal. Los grupos están compuestos de individuos, las excepciones confirman las reglas y los promedios no encajan con nadie generalmente. 
El panorama cambia sustancialmente si el punto de partida se sitúa antes de la llegada de los españoles y lo hace también si nos retrotraemos a la Mesoamérica anterior a la expansión culhúa-mexica. Para empezar, las categorías étnicas que manejamos son completamente distintas y como es un concepto utilizado preferentemente, cualquier variación tiene consecuencias inmediatas. En el período prehispánico no se maneja el concepto «indio». Para el México central hablamos de tepanecas, mexicas, acolhuas, otomíes, matlatzincas, etc. y si ampliamos un poco el área, tendremos zapotecas, mixtecas, totonacas, mayas de diferentes denominaciones, etc. Y ni siquiera estamos seguros de que estos grupos sean los conceptos de referencia para los señores antiguos, pues una afiliación reiterada es con linajes concretos o con entidades geográficas. Estas identificaciones eran significativas antes de la llegada de los españoles, pero hemos tendido a eliminarlas para tiempos posteriores al agruparlos a todos bajo el concepto «indio», o para el caso de este trabajo «nobleza indígena», sin considerar seriamente si las identificaciones antiguas seguían estando vigentes, pese a ejemplos como el comportamiento de los tlaxcaltecas en el mundo colonial.

Un ejemplo reciente de preguntas acertadas y de comparación entre la situación prehispánica y la colonial, lo constituye el artículo de John K. Chance y Barbara L. Stark (2007) sobre las estrategias provinciales en el Imperio mexica y en el mundo colonial. Su cuadro 1 (Chance y Stark 2007: 208) ofrece una síntesis de las estrategias analizadas, que son: reforzamiento, resistencia, emulación, éxodo, control de la información, apropiación, afirmación, complicidad y asimilación. En la mayoría de ellas tienen un papel importante las estrategias personales y son de mayor influencia las de las elites, pero también tienen presencia el resto de los pobladores. Cada uno obra según sus posibilidades e intereses.

Hay aún una consideración que hacer antes de entrar en la materia de este artículo: la aplicación de los conceptos de emic y etic a los contextos temporales. Es frecuente que lo hagamos con diferencias culturales y, en cambio, poco habitual que lo consideremos para los distintos tiempos. En este caso habrá que considerar que el mundo que vivieron los señores anteriores a las conquistas mexicas, el ambiente de los señores que convivieron con el imperio de Tenochtitlan, las circunstancias que rodearon a los que gobernaban en los primeros tiempos coloniales y las de sus sucesores en los distintos siglos de la dominación española, fueron todos parecidos y al mismo tiempo diferentes. Podemos trazar una evolución, pero también podemos encontrar marcadas diferencias entre unos y otros. Y es importante para nosotros al hacer este análisis insistir en que las motivaciones de cada uno debemos buscarlas en su entorno, no en el nuestro. Cada uno en su lugar y en su tiempo y es a eso a lo que nos referimos al hablar de una postura «emic temporal».

Así que hay que atender a lo que ellos dicen y a lo que hacen. Buscar allí las razones que nos permitan comprender los comportamientos. Eso no quiere decir que debamos creer al pie de la letra todo lo que dicen, pero el que lo digan también es una evidencia. El tipo de documentos que los señores indígenas produjeron es también una prueba de lo que pensaban, comprendían y hacían.

Y vamos a comenzar precisamente por un tipo documental muy abundante: las genealogías. Hay algunas evidencias prehispánicas, como el Códice Nutall y el Códice 
Vindobonensis Mexicanus, pero la mayoría son coloniales, en algunos casos tardías. Tenemos ejemplos en forma de códices, como el Códice Baranda, la Genealogía de los Señores de Etla, la Genealogía de la familia Mendoza Moctezuma,la Genealogía de una familia de Tepeticpac, que son fundamentalmente historias de linajes, y otros en los que los linajes aparecen solamente en parte, como el Códice Xolotl, por citar solamente algunos ejemplos. Una genealogía particularmente atractiva es la que aparece en el Códice García Granados, en forma de nopal, en el que se muestran los miembros del linaje de Tlatelolco desde el periodo prehispánico hasta el siglo XVII. Hay muchas muestras del interés que los señores indígenas de distintos rangos manifestaron en certificar sus ascendientes y con ello tratar de legitimar sus derechos. Otras muchas genealogías se encuentran escritas en caracteres latinos dentro de largos expedientes, generalmente pleitos, desde el siglo XVI al XVIII, o en relatos como la Crónica Mexicayotl, generalmente atribuida a D. Hernando Alvarado Tezozomoc, miembro de la familia que describe. Genealogías tenemos también en la fundación de mayorazgos, que también ilustran sobre las luchas entre los diferentes pretendientes a una misma herencia. En muchos casos esas familias exhibían escudos de armas concedidos por el rey de España a quienes demostraron su colaboración con los españoles en la conquista (ver Fernández de Recas 1961).

Un caso interesante de documentos que mezclan cuestiones genealógicas con derechos sobre tierras, tributos y vasallos, está constituido por los llamados Títulos Primordiales (ver Rojas 2006). Estos documentos que generalmente se han asociado con derechos de los pueblos, deben pasar a ser vinculados en muchos casos con facciones, linajes o personas concretas. Esta deducción procede fundamentalmente de los estudios de Robert Haskett sobre Cuernavaca (por ejemplo hay 8 en Haskett 1990: 132 y son ya 16 en Haskett 1998: 139), en los que el número de Títulos Primordiales de la población ha ido creciendo y cada uno se ascribe a una facción distinta. A partir de ahí hay que buscar más casos y estar atentos a las variantes. Por ejemplo, Dyckerhoff (1998) informó de que el pueblo de Huaquilpan tenía un documento en nahuatl, que llamaban tlalamatl y un códice de tipo Techialoyan. Es muy posible que estos tipos estén vinculados, que respondan a una misma motivación, y que las diferencias se deban a las opciones que cada uno escogió pensando que le darían mejor resultado. $\mathrm{Y}$ eso pudo ocurrir en pueblos distintos o en el interior del mismo pueblo. En todos los casos se trata de demostrar la posesión ancestral de algo y apoyar el derecho en aquel momento a tenerlo. En este momento lo de menos es que esos derechos existieran o no, aunque la fabricación de documentos ex-profeso podría relacionarse con los documentos legales de quienes sí tenían derechos antiguos y podían pedir copias de los documentos, ya sean cédulas, contratos o testamentos (ver Sousa y Terraciano 2003; Rojas 2006, Romero 2010 y Wood 1989 y 1998 para falsificaciones o hechura de documentos). Todos parece ser que perseguían algo similar y eso es lo que nos interesa más en este momento. Incluso a finales del siglo XIX y comienzos del siglo $\mathrm{XX}$ se seguían haciendo documentos que «probaban» los derechos de los pueblos (ver Barrera y Barrera 2009), ya finales del XX y comienzos del XXI su uso continúa (Romero 2010). 
Una de las preguntas que se nos ocurren es si los señores indígenas de la colonia se sentían descendientes directos de sus antecesores prehispánicos y si era así, si sentían que existía una continuidad en la estructura social y en las entidades de poder. El retrotraer sus genealogías a los tiempos prehispánicos parece indicarlo así, o bien es una muestra de la comprensión de que los españoles estaban reconociendo derechos prehispánicos a los señores indígenas. En realidad, en muchos casos, se trataba de derechos pre-mexicas. En otros ejemplos, las genealogías se remontaban solamente a los tiempos de la conquista española, destacando el papel que los antepasados habían tenido en la derrota de los mexica de Tenochtitlan. Cada uno elegía lo que pensaba que le daba mejores posibilidades y elegía la normativa que más le convenía, ya fuera la tradicional indígena, ya fuera la legislación española.

Sentirse descendientes no quiere decir que pensaran que nada había cambiado, más bien todo lo contrario: si eran capaces de invocar leyes diferentes según sus intereses, eso indica el elevado grado de comprensión de las novedades que tenían.

Nos vamos a referir preferentemente a dos, estrechamente vinculadas, pues ambas tienen que ver con el matrimonio: la monogamia y el llamado mestizaje. Antes de la llegada de los españoles hubo una activa política matrimonial que vinculaba a los señores de distintos lugares entre sí. Dada la posibilidad de que un varón contrajera matrimonio con cuantas mujeres quisiera, las alianzas matrimoniales se hacían de manera personal y existía una compleja jerarquía de parejas, vinculada a la importancia del linaje de la mujer más que a su edad o al orden en que se contraían los matrimonios. Es decir, la esposa principal era siempre la que procedía del linaje dominante y eso no cambiaba mientras no hubiera cambios políticos que alteraran la jerarquía de los lugares, como ocurrió con la independencia de Tenochtitlan frente a Azcapotzalco (ver Santamarina 2006: 63-67). El sistema además señalaba quienes iban a heredar los diferentes señoríos, que también estaban jerarquizados. El cambio en el mundo colonial fue muy grande en este aspecto, al pasar a la monogamia y tener cada señor una sola esposa. Las alianzas matrimoniales se podían hacer ahora solamente con el matrimonio de los hijos y no personalmente, y las posibilidades eran mucho más limitadas. No obstante, también había ventajas, pues la escasez de herederos permitió la acumulación de herencias y conforme pasó el tiempo hubo más señoríos en manos de un solo señor. Un ejemplo paradigmático de estas acumulaciones es D. Martín de Villagómez que en el siglo XVIII llegó a tener más de 30 señoríos (ver Chance 2009). Este es un tema al que hemos prestado poca atención y sería menester trabajar más en esta línea. Cabe la posibilidad de que hayamos considerado homónimos a quienes eran una sola persona, por no estar atentos a la posibilidad de que gobernaran en más de un sitio a la vez. Darse cuenta de que el Constantino Huitziméngari de principios del siglo XVII que aparece en Tzintzuntzan y en Coyoacán es el mismo, puede ser sencillo por lo insólito del nombre, pero identificar a un Moctezuma, un Cortés o un Mendoza como la misma persona requiere más trabajo. Y el tema es muy importante. Entre otras cosas porque da la razón a quienes ven que a finales del mundo colonial había menos señores, pero también nos muestra que los que había podían ser mucho más poderosos y haber extendido sus dominios por muchas regiones distintas. 
De todos modos, no debemos olvidar que el paso de la poligamia a la monogamia no fue inmediato y muchos señores indígenas, incluso bautizados, continuaron teniendo distintas esposas y manteniendo el sistema de alianzas que había antes de la llegada de los españoles. Un ejemplo de esto se puede ver en los padrones de Morelos, y para Martín Molotecatl tecuhtli, en el trabajo de Carrasco sobre su casa, basado en los mencionados padrones (Carrasco 1972).

El segundo cambio es, precisamente, la presencia de los españoles. Con ellos se produjo un cambio en las relaciones de poder y los maridos y mujeres españolas entraron en el juego de las alianzas matrimoniales. Al comienzo, preferentemente maridos, pues había pocas mujeres, pero estas fueron llegando y sumándose a las hijas de españoles que nacían en la Nueva España. Generalmente llamamos mestizos a los hijos de tales uniones, pero parece cada vez más claro que el término tardó en usarse en la forma en que ahora lo hacemos. Un ejemplo de los problemas que la categoría «mestizo» crea a los investigadores, nos lo proporciona el ya clásico estudio de Jonathan Israel (1980) que habla en muchos casos de «españolas» para referirse a las hijas mestizas de los españoles, que eran esposas deseadas cuando eran de clase alta (Israel 1980: 69). Israel hace verdaderos esfuerzos para aunar lo que pasaba y lo que «debería pasar», es decir, que había mestizos biológicos, pero no aparecían como tales. Nosotros haríamos bien en escarmentar en cabeza ajena y aprender la lección que párrafos como los siguientes encierran:

«Si bien no se necesitó mucho tiempo para que los niños mestizos abundaran, en un principio no formaron parte de un tercer elemento o grupo diverso de la sociedad indígena o de la sociedad española, pues a pesar de ser mestizos vivían o como «españoles» o como «indios». Los hijos legítimos y los ilegítimos de madres procedentes de la aristocracia indígena, o que por alguna razón estaban reconocidos por sus padres, fueron absorbidos por la primera generación de criollos, los cuales eran, en muchos casos, mestizos» (Israel 1980: 69-70).

Da algunos ejemplos, como las hijas de Cortés, o los matrimonios de Isabel de Moctezuma, para reconocer que eran los descendientes de padres de clase baja los que no tenían entrada en ese mundo «español». Pero en vez de seguir esa línea se empeña en seguir la pista a los escurridizos mestizos:

«Los primeros mestizos, pues, aun cuando fueran bilingües y a pesar de su compleja psicología, solían estar clasificados socialmente o como «españoles» o como «indios», los matrimonios entre mestizos y mestizas, la existencia reconocida de la familia mestiza propiamente dicha, eran hasta cierto punto raros, y muy pocos mestizos estaban clasificados como miembros de un tercer grupo de la sociedad. Cabe suponer que aquí reside la paradoja de los mestizos del siglo XVII, los cuales eran numerosos e importantes al mismo tiempo que parecían ser escasos y tener poca importancia: la mayor parte llevaba una vida social disfrazada. La verdadera población «mestiza», o sea, la que en la sociedad mexicana del siglo XVI era calificada como tal, crecía y se desarrollaba al margen de la «república española» y a la sombra de los negros» (Israel 1980: 70-71).

Este párrafo ilustra de manera magnífica la necesidad de aplicar los conceptos de etic y emic al estudio del pasado. Israel encuentra que para la gente mexicana del 
siglo XVI, «mestizo» era algo diferente a lo que él cree que debe ser. Es decir, trata de hacer primar la visión etic sobre la emic, y resulta que no funciona. Es importante señalar que, aunque la cita empleada sea del mencionado autor, el mismo problema lo hemos tenido todos. Y lo que es necesario hacer es aprovechar las evidencias para ver cómo entendían la sociedad los que vivían en ella. Al hacerlo, encontramos explicaciones más sencillas casi siempre.

En este caso, es procedente preguntarse sobre el significado de los distintos términos, como en su día lo hizo Karen Spalding (1974) para el Perú con los indios. Al preguntarse ¿qué es el indio?, en realidad se vió obligada a plantearse qué es un español, un mestizo, un pardo, etc, , pues estas categorías étnicas forman en realidad variables dependientes y si cambiamos el significado de una nos vemos obligados a cambiar el de las otras. Y si no lo hacemos, volvemos a caer en la incomprensión. Una reflexión de Spalding muy pertinente para la Nueva España es la obligación que los señores locales tuvieron de seguir siendo indígenas para seguir siendo señores (Spalding 1974: 184). Pero esa obligación solamente afectaba al heredero, no a sus demás parientes que podían elegir la adscripción que más les conviniera, y si Spalding hubiera ido más allá en sus reflexiones habría matizado sus siguientes frases:

«La considerable riqueza y posición de muchos de los miembros de la nobleza india es enfatizada por el hecho de que muchos casos de disputas sobre el derecho de sucesión al cargo y a las posesiones de una familia noble india - un cacicazgo-, resultaron la falsificación de genealogías hechas por los miembros de la sociedad europea que trataban de pasar como miembros de la nobleza indígena» (Spalding 1974: 175).

Pues en realidad nadie necesita falsificar nada, sino que podría darse el caso de que fueran realmente parientes que «habían abandonado» el mundo indígena y de repente necesitaban volver a pertenecer a él. Y tenían todo el derecho tanto a una cosa como a la otra, pues su descendencia era doble y estaban orgullosos de ella, como por otra parte sí menciona Spalding (1974: 162).

Si la nobleza indígena continuó formando parte de la elite, con todas las matizaciones que se quieran hacer, pues había muchas diferencias entre unos señores y otros, y los españoles o al menos una parte de ellos, pasaron a formar parte de esas elites, ¿no deberíamos considerar que los matrimonios entre españoles e indios seguían siendo alianzas entre las elites? y en algunos casos, como el mencionado por Israel (1980: 70) de la hija de Pedro de Alvarado y Leonor Xicotencatl con un primo del duque de Albuquerque, Grande de España, o el más sonado de la nieta de Sayri Tupac con un nieto de San Francisco de Borja, duque de Gandía, también Grande de España, que selló la alianza entre las casas de Loyola y Borja y los descendientes de los Incas, recibiendo la pareja el marquesado de Santiago de Oropesa (ver Lohmann 1948-49), el asunto parece claro. Dadas las intrincadas relaciones de parentesco de los Borja, Da Ana María Coya emparentó con las principales casas nobles españolas, incluyendo varios virreyes del Perú, como Martín Enríquez de Almansa y el Príncipe de Esquilache, a finales del siglo XVI y principios del XVII. Como hemos primado el componente étnico sobre las familias, no hemos investigado la importancia que esas relaciones tuvieron y quizás vaya siendo hora de hacerlo. Algo nos hemos preguntado sobre las relaciones de los hijos de Moctezuma con Hernán Cortés, emparentados 
a través de la hija que el conquistador tuvo con Isabel de Moctezuma (Rojas 2001, 2010), pero sería necesario ir más allá, tomando las elites coloniales como conjunto y analizando sus vínculos y relaciones. Y su evolución, pues cuando hacemos un seguimiento de los linajes nobles encontramos ramas muy indígenas y otras completamente hispanizadas, a veces muy cercanas unas a otras y es muy probable que las razones de estas adscripciones tengan mucho que ver con lo comentado por Spalding. De esa forma, por ejemplo, muchos hijos de la nobleza indígena pudieron ordenarse sacerdotes sin incumplir ninguna norma, pues como descendientes de españoles tenían todo el derecho. Una familia que nos puede ilustrar sobre este pormenor es la del conocido cronista Fernando de Alva Ixtlilxochitl (Munch 1976, sobre todo el Apéndice II). Dos cacicas sucesivas, $D^{\text {a }}$ Francisca Cristina Verdugo Quetzalmamalitzin (1580-1597) y su hija $\mathrm{D}^{\mathrm{a}}$ Ana Cortés Ixtlilxochitl (1597-1639), casadas con españoles (Juan Grande y Juan Navas Pérez de Peraleda respectivamente) dieron paso a un cacique, D. Francisco de Navas Huetzin (1639-1645) casado con española (María Caballero o Manrique), quienes no tuvieron hijos, por lo que el cacicazgo pasó a un hijo del cronista D. Fernando por haber muerto este, D. Juan de Alva y Cortés, quien tuvo que pleitear para disfrutarlo. Otro hermano del cronista fue D. Bartolomé de Alva, presbítero, cura beneficiado de Zumpango y autor, entre otras obras, de un confesionario nahuatl (Alva 1634), lo que deja bien clara la «complejidad étnica» de la familia.

Es mucho el camino que se ha recorrido en los últimos años, pero aún queda mucho por andar, entre otras cosas porque cuanto más crece el conocimiento más vías nuevas se abren. Una de ellas es la valía del conocimiento del mundo colonial para aprender más del prehispánico y para ello tiene un enorme interés la posición de los implicados, es decir la visión emic. Si la nobleza indígena colonial remontaba sus derechos hasta los señores prehispánicos es que veían un nexo, una identificación entre unos y otros. Y una parte importante de los nobles titulados en vísperas de la Independencia se declaraban descendientes de Moctezuma y lo hacían para dar mayor alcurnia a sus ancestros (ver Ladd 1984). Además, revisando las genealogías, no era una mera pretensión, sino una realidad fruto de la activa política matrimonial llevada a cabo durante siglos.

Para analizar las similitudes y diferencias que había entre los señores prehispánicos y los coloniales es práctico comenzar por su punto de contacto, que es el momento de la conquista. En él ha sido tradicional cargar las tintas sobre la actuación de los españoles y minimizar la participación indígena, salvo para el caso de los tlaxcaltecas, pero algo está cambiando y cada vez estamos en mejores condiciones de analizar el papel de los indígenas, sobre todo de los señores, en el momento de la conquista (Rojas 2007). Pero no acaba ahí el asunto; como ya hemos visto muchos señores indígenas coloniales invocaron los méritos de sus antepasados, no solamente en la caída de Tenochtitlan, sino en muchos momentos posteriores, como las conquistas de Oaxaca y Guatemala, la guerra del Mixtón o las guerras chichimecas. Sobre el papel de los tlaxcaltecas en esas campañas se han publicado diversos trabajos recientes, algunos en la misma Tlaxcala, cuyo interés es grande (Martínez Baracs 1993, 2008; Sego 1998; Valdés y Dávila 1999; Martínez Saldaña 2004; Cuadriello 2004) pero para el tema que nos ocupa ahora el momento importante es el de la caída de Tenochtitlan. 
Al menos desde la primera aparición del Cacique Gordo, la posición preeminente de los señores indígenas se ve con claridad. Más tarde, en Tlaxcala, la discusión entre apoyar o combatir a los españoles vuelve a producirse entre los gobernantes de la ciudad y sus parientes más cercanos. Otro caso claro se produce en Texcoco, donde los problemas sucesorios a la muerte de Nezahualpilli eran muy recientes, y donde van a volver a producirse diferencias durante la conquista, favoreciendo la alianza de Ixtilxochitl con Cortés, que a la larga le supuso el gobierno de la ciudad, no sin nuevos conflictos (ver Madajczak 2007). Conflicto es una palabra clave para entender los comportamientos de los señores. Aunque hasta 1994 no comenzó a hablarse de «facciones» para referirnos a la política mesoamericana (Brumfiel y Fox 1994), la existencia de estas está bien clara en lo que sabemos de la política mesoamericana. La historia de 8 Venado Garra de Jaguar es un ejemplo de facciones opuestas, como lo es la sucesión de Tezozomoc de Azcapotzalco y la guerra que los tenochcas encabezaron contra Maxtla (ver Santamarina 1998, por ejemplo). La misma muerte de Moctezuma puede ser englobada en esta lucha de facciones: Cuitlahuac necesitaba que el huey tlahtoani muriera para poder acceder al cargo (ver Batalla 1996 para una evaluación de las diferentes versiones). La existencia de estas facciones es clave para entender el funcionamiento de la política mesoamericana, en la que las guerras y las conquistas estuvieron presentes desde mucho tiempo antes de la llegada de los españoles. La formación de imperios, las alianzas entre señores, matrimoniales o políticas, o frecuentemente ambas cosas, son fruto de los intereses personales de muchos individuos que buscaron aliarse con quien mejores perspectivas les ofreciera. La información que tenemos no profundiza mucho en el tiempo, pero da las suficientes claves para comprender la situación, si es que queremos hacerlo, pues hasta la lucha entre Tezcatlipoca y Quetzalcoatl en la creación y destrucción de los distintos soles cosmogónicos, podría ser interpretada como una lucha entre facciones de dioses. Y la derrota y expulsión de Quetzalcoatl de Tula, otro tanto. Conocemos bastante del desarrollo del imperio mexica, y mucho menos de los tiempos anteriores, cuando el estudio de estos lo que nos ha demostrado es que la mayoría de las prácticas mexicas tenían precedentes en Mesoamérica, con la posible salvedad del tamaño de lo conseguido. Si estudiamos el período anterior a la fundación de Tenochtitlan y los primeros años de ésta, no desde la perspectiva de la migración y aventuras de los futuros amos del Anahuac, sino desde la óptica del poder entonces dominante y la forma en que éste se ejercía, las circunstancias cambian y la épica historia de los tenochca se convierte en una lucha muy mesoamericana por ascender en la escala política del centro de México y eventualmente alcanzar la cima, como nos ha mostrado reiteradamente Santamarina (2002, 2005a, 2005b, 2005c, 2006). Este conocimiento de los métodos mesoamericanos facilitó el éxito de los tenochcas que sabían muy bien cómo tenían que afrontar los problemas y resolverlos a su favor. Un ejemplo de ello fue la rebelión de Cuauhnahuac a mediados del siglo XV. En un proceso similar al que habían experimentado los tenochcas, Cuauhnahuac fue acumulando poder hasta que pensó que era suficiente para desafiar a Tenochtitlan pero esta le demostró que estaba equivocado, aplastando la rebelión (Smith 1986: 79). 
A mediados de la década de 1980 apareció una obra en la que se postulaba que la organización del estado mexica era de tipo hegemónico (Hassig 1985), en el que los estados sometidos jugaban un papel fundamental en la estructura del imperio. La misma idea permanece en obras posteriores (Hassig 1988, 1994), apareciendo más explícitamente el papel de los señores:

«The Aztecs merely tapped into the existing system, positioning themselves at the top. This tribute payment was a net loss to the subject towns but conquest typically caused few other overt changes in the local society. Except in the case of recurrent rebellion, conquered rulers remained in place and exercised local control, which freed the Aztecs from the local administration and allowed them to continue their military expansion» (Hassig 1994: 30-31).

Hassig habla de estados y Smith (1986) fue más allá, haciendo más énfasis en los señores:

«It is my contention that the primary force binding the empire together was the common interest of the Postclassic Mesoamerican nobility. Provincial ruling dynasties cooperated with the rulers of the Triple Alliance states in the economic exploitation of their local commoners. Social stratification may thus be singled out as one of the most important factors in the integration of much of the empire» (Smith 1986: 70).

Y una vez incorporados, los señores locales se podían beneficiar de su pertenencia al imperio, de manera que lo que perdían por una parte lo podían ganar por otra (Hodge 1991: 134-135). Berdan (1994: 299) lo resumió con claridad:

«Upon conquest by the Mexica and their allies, a city-state was typically allowed to retain its traditional ruler(s) and noble-level integration into the imperial structure was solidified through marriage alliances, gift exchanges, and common participation in religious ceremonies and political events».

En algunos casos los señores locales no tuvieron que esperar mucho para obtener su recompensa, pues su colaboración en la conquista de una región les permitió mejorar su posición en la misma, como ocurrió con Tepeacac y la conquista de Cuauhtinchan por los mexica. Los colaboradores recibieron recompensas por su ayuda y pasaron a ocupar el puesto prominente en la nueva situación (Rojas 1994a), aunque su poder dependiera ahora de los señores imperiales y los necesitaran para seguir gobernando, como señala Hicks analizando los casos de Cuauhtitlan, Tollan y la mencionada Tepeacac:

«Military force was involved in all three cases, but it was more than simply an attack by the imperial forces on those of another state, resulting in the defeat and surrender of the latter. What we find is that the imperial forces intervened in local or internal affairs, supporting one side or faction against the other. If the intervention was succesful, it was the nobles of the favored faction, not all nobles, who benefited from being in the empire, and their benefits came at the expense not only of their commoners, but also of the other nobles. The favored nobles, as Brumfiel (1983: 273-4) points out, become the most powerful in their domain, but also the most dependent on the Triple Alliance, for only with its backing could they retain their power» (Hicks 1994: 111). 
Las luchas internas locales favorecieron la formación del imperio y le dieron cohesión a través de los lazos matrimoniales y la necesidad que los señores locales tenían del apoyo del poder superior para defenderse de sus enemigos más cercanos. Además, su fidelidad era recompensada, participando en sucesivas campañas de conquista y recibiendo recompensas por ello, de manera que podían compensar la parte de sus ingresos que debían pagar al huey tlahtoani. Incorporarse al imperio culhuamexica ofrecía oportunidades de prosperidad a quienes lo hacían.

Un problema interesante, que tiene que ver de nuevo con las visiones emic y etic, es la elección de las unidades de análisis para el período prehispánico. Deliberadamente estamos hablando de señores y no de ciudades o de estados, siguiendo las ideas que Rik Hoekstra (1990) expuso sobre la forma de organización del México prehispánico, basada en la personenverband y no en la territorialverband, que más o menos podemos simplificar diciendo que era un mundo de señores, no de territorios. Siguiendo esa línea, podríamos decir que un tlahtoani no es quien gobierna un tlahtocayotl, sino que un tlahtocayotl es lo que pertenece a un tlahtoani y no se trata solamente de tierras, sino de un complejo sistema de relaciones, sobre todo personales, como se percibe muy bien en el trabajo de Hildeberto Martínez sobre Tepeaca (1984). Y leyendo a Bernal Díaz del Castillo o a Hernán Cortés, se aprecia como México aparece siempre como un lugar, mientras que las menciones al gran señor Moctezuma como dueño de todo son constantes.

El mundo prehispánico aparece como un continuo conflicto de intereses. Conflictos entre los gobernantes centrales y los locales, conflictos entre los aspirantes al gobierno, con momentos delicados siempre que se producía un cambio de gobernante, conflictos entre las diferentes capas sociales. Por eso, a veces las estrategias de unos y otros son opuestas, y las alianzas son cambiantes. Cada uno buscaba asociarse con quien le ofrecía más ventajas o más posibilidades de éxito. Volviendo a Chance y Stark, las diferentes estrategias ofrecían aspectos distintos según quienes intervenían:

«Por último, subrayamos la importancia de las perspectivas de los protagonistas en la discusión de las estrategias provinciales. Aunque las estrategias imperiales emanaban de las autoridades del gobierno central y respondían estrechamente a los intereses de la elite o clase gobernante, las estrategias provinciales pueden exponer más fácilmente acciones independientes e intereses de un espectro social que incluye a los macehuales o a comunidades subordinadas. Reconocemos importantes diferencias en las estrategias provinciales de acuerdo con la clase $\mathrm{u}$ otros intereses faccionales $\mathrm{o}$ de identidad» (Chance y Stark 2007: 208).

Asumir una estrategia determinada no quiere decir acertar. Como ya hemos comentado, Cuauhnahuac desafió a Tenochtitlan y fue derrotada. Pero tampoco es una cuestión de extremos, de blanco o negro, sino que hay muchos matices intermedios y muchos de ellos tienen que ver con los objetivos que cada uno tiene cuando se embarca en un proceso. Si elegimos mal el punto de comparación, podemos equivocarnos fácilmente. Veamos un significativo párrafo de Ross Hassig sobre la Conquista de México:

«The Aztecs fought a Mesoamerican war and lost. They chose to defend their capital on the assumption that they would gain defensive military advantage and the stringent 
logistical constraints on Mesoamerican warfare would work in their favour. However, technological innovations and, more importantly, political shifts stripped the Aztecs of these advantages. But if the conquest of Mexico was an Indian victory over Indians rather than an Spanish victory over Indians, why did all the Indians fare so poorly thereafter? The answer can be largely found in the different goals pursued by the Indians and the Spaniards» (Hassig 1994: 146-147).

Diferentes fines, he ahí una de las claves. Hassig presentó una novedosa interpretación de la conquista, pero en vez de conducirle a una nueva evaluación de la situación colonial, no cambió el discurso para ésta. Creemos que el error se encuentra en los puntos de comparación que utiliza y en la inclusión de la palabra «todos» en los destinos de los indios coloniales. Su interpretación de la conquista española deja clara la existencia de indios vencedores, y en lugar de seguirles la pista y evaluar sus recompensas, reduce todo al sometimiento a los españoles, que indudablemente se produjo. Es interesante citar la actitud de Cortés nada más terminar la guerra de conquista:

«Después que Dios Nuestro Señor fue servido que esta gran ciudad de Temixtitán se ganase, parecióme por el presente no ser bien residir en ella, por muchos inconvenientes que había y paséme con toda la gente a un pueblo que se dice Cuyuacán, que está en la costa de esta laguna, de que ya tengo hecha minción, porque como siempre deseé que esta ciudad se edificase, por la grandeza y maravilloso asiento della, trabajé de recoger todos los naturales, que por muchas partes estaban ausentados desde la guerra, y aunque siempre he tenido y tengo el señor della preso, hice a un capitán general que en la guerra tenía, y yo conocía del tiempo de Muteczuma, que tomase cargo de tornarla a poblar. Y para que más autoridad su persona tuviese, tornéle a dar el mismo cargo que en tiempo del señor tenía, que es ciguacoat, que quiere tanto decir como lugarteniente del señor; y a otras personas principales, que yo también asimismo de antes conocía, les encargué otros cargos de gobernación desta ciudad, que entre ellos se solían hacer; y a este ciguacoat y a los demás les dí señorío de tierras y gente, en que se mantuviesen, aunque no tanto como ellos tenían, ni que pudiesen ofender con ellos en algún tiempo; y he trabajado siempre de honrarlos y favorecerlos» (Cortés, Cuarta carta, 1979: 217).

En el mismo siglo XVI, otras opiniones no solamente están de acuerdo con la declaración de Cortés, sino que la amplian:

«Cuando se ganó la Nueva España se quedó en ella esta manera de gobierno entre los naturales, y les duró algunos años, y sólo Moctezuma había perdido su reino y señorío, y puéstose en la Corona Real de Castilla y algunos de sus pueblos encomendádose a españoles, y todos los demás señores de las provincias a él sujetas y no sujetas: y los de Texcoco y Tacuba poseían, mandaban y gobernaban sus señoríos y gozaban de ellos, aunque estaban en cabeza de vuestra majestad o de encomenderos, aunque no les quedaron tantas tierras y vasallos como primero tenían, y les acudían con las sementeras y tributos como antes que se ganase la tierra, y eran obedecidos y temidos y estimados, y a ellos acudían los pueblos que les quedaron, con los tributos que daban a vuestra majestad y a los encomenderos; y tenían puestas personas para cobrarlos, y de manos del señor lo recibían y cobraban los oficiales de vuestra majestad en los pueblos que estaban en su real cabeza, y los encomenderos de lo que ellos tenían. Así estaban todos los señores en su gravedad y autoridad antigua, muy obedecidos de sus súbditos, 
y los servían en su modo y manera antigua, acudiéndoles con sus tributos y servicios» (Zorita 1891: 99-100).

Si los señores estaban «en su gravedad y autoridad antigua» es que no les había ido tan mal. Y si los señores que estaban así no eran los que había antes, sino los que habían conseguido ser señores con su actuación en la Conquista al lado de los españoles, deberíamos ser capaces de reconocer que individualmente habían mejorado, como fue el caso de D. Fernando Ixtlilxochitl y de tantos otros. Si muchos señores indígenas habían participado en aquella «guerra mesoamericana» para conservar sus privilegios y lo habían conseguido, suponemos que estaban satisfechos, como lo habrían estado de saber que sus descendientes iban a seguir ocupando cargos de privilegio hasta el final del dominio español. Ninguno de ellos fue emperador, pero probablemente ninguno de ellos lo pretendió, así que Moctezuma o Cuauhtemoc no son buenos puntos de comparación, ni siquiera para los miembros de su familia que nunca pensaron que pudieran heredar el imperio y que, en cambio, dejaron bien claro el mundo de facciones mesoamericano en sus pugnas por la herencia y los privilegios que la corona otorgó a los descendientes del huey tlahtoani (Rojas 1994b).

Volvamos con los indios vencedores, que no son solamente los que estaban en el mismo bando que Cortés cuando se produjo la caída de Tenochtitlan. Consideramos también «vencedor» a quien estaba relegado en un orden sucesorio y de repente se vió aupado a un cargo de gobierno, aún cuando no tuvieran participación en esa escalada. Es decir, en algunos casos el fallecimiento en la guerra de quien estaba delante abrió el camino a quien lo tenía cerrado, propiciando su ascenso a un lugar preferente. Y de la misma manera que ocurrió con la incorporación al imperio mexica, estos nuevos señores estaban en deuda con la administración central española y dependían de ella para permanecer en sus puestos. De grado o por fuerza, pues, eso los hacía colaboradores del nuevo régimen, en el cual buscaron prosperar. Participaron en conquistas para obtener privilegios, o se embarcaron en luchas locales para variar la correlación de fuerzas dentro de una región, de forma similar a lo que sucedió entre Cuauhtinchan y Tepeacac, que ya hemos comentado. Muchos señores formaron parte de la nueva administración, sirviendo a la Corona como jueces, gobernadores o intérpretes (ver Rojas 2010, cap. 5, «Los señores al servicio de la administración»). Continuaron estableciendo alianzas matrimoniales y ampliando con ellas su ámbito de influencia, favorecidos esta vez por la reducción de señores que impuso la monogamia, al concentrar diversos títulos en un único heredero.

Algunos de estos señores no eran «legítimos», sino que se habían alzado con el poder durante la Conquista o en los tiempos inmediatamente posteriores, pero la legitimidad es un concepto variable, que depende muchas veces de decisiones previas. Veamos un caso:

«Desde que fueron conquistados estos pueblos deste distrito por los señores de México, no tuvieron señor natural, porq[ue] era costumbre del vencedor matar y apocar las cabezas de los señores del pueblo vencido, por mejor lo asegurar. Y luego ponían [a] un recaudador mexicano que tuviese cuenta de cobrar los tributos del pu[ebl]o y acudir con ellos a los señores de México. Estos recaudadores que había en este distrito, en la conquista de México y revolución de la tierra, cuando don HERNANDO CORTÉS, 
Marqués del Valle, vino a conquistarla, se quedaron introducidos por señores de los pueblos que a su cargo tenían, y así, quedaron por señores dellos, sin que se apurase la verdad dello. Esto se entiende no generalmente de todos los pueblos, porque, en algunos, había señores naturales, aunque pocos, que aliados con los señores de México y reconociéndoles señorío, se quedaban en el suyo» (Relación de Atlitlalaquia 1580: 62-63).

Esta cita ilustra muy bien el problema de la legitimidad de los señores confirmados por Cortés, que podían ser los señores naturales del pueblo, los impuestos por los tenochcas o las dos cosas a la vez, pues era práctico confirmar a quien ya tenía derechos. Desde este punto de vista, igual que hubo un reacomodo de las dinastías gobernantes cuando Tenochtitlan alcanzó la hegemonía, y debió haberlo cuando Azcapotzalco se convirtió en el centro de referencia, volvió a haberla después de la caída de Tenochtitlan. En relación con este tema es muy sugerente la lectura de Lockhart y Schwarz (1992: 42-55) sobre los «pueblos imperiales» prehispánicos. Destaquemos dos párrafos:

«En general, los fenómenos a gran escala más espectaculares del mundo indígena anterior a la conquista no son tan importantes para la situación posterior a la misma como ciertos mecanismos, menos visibles, radicados en el nivel provincial, mecanismos que sobrevivieron a los imperios y que igualmente podrían apoyar una presencia europea» (Lockhart y Schwartz 1992: 42).

«No obstante, adoptaremos en ese capítulo un procedimiento diferente, concentrándonos en un nivel intermedio situado entre el poblado local y el gran imperio: una unidad provincial del orden de magnitudes similar al de un condado europeo, o algo más pequeño a veces, aunque no siempre centrado en un núcleo urbano. Existen dos razones para proceder de este modo. En primer lugar, la unidad provincial habría de revelarse como la más importante tras la llegada de los europeos; al mantener su integridad después de la conquista, condicionó el tamaño y la configuración de las jurisdicciones y proporcionó los mecanismos que habrían de permitir una concentración de la presencia europea. En segundo lugar, e igual de importante, había muchos aspectos del entramado global que no existían en niveles más pequeños o,si era el caso, sólo servían a tal propósito dentro de un contexto provincial, por lo que en muchos aspectos la provincia era la unidad más pequeña dotada de un sentido inteligible en sus propios términos» (Lockhart y Schwartz 1992: 43).

Y estas unidades eran también indígenas, anteriores a la existencia de imperios, al menos los últimos y, en muchos casos, recién incorporadas al dominio mexica, lo que nos debería hacer preguntarnos qué grado de satisfacción tenían. Y eso sin olvidar a quienes nunca formaron parte de esos imperios. Lo que merece la pena es investigar el comportamiento de esas unidades que nosotros sugerimos identificar con sus cabezas, es decir, los señores, durante lo siglos de dominio español y decidir después cómo les fue. Y así, este final,vuelve a ser un comienzo y los artículos que siguen son una buena muestra de las posibilidades que la investigación ofrece. 


\section{Referencias bibliográficas}

ACUÑA, René

1985 Relaciones Geográficas del siglo XVI. Tomo 6, México tomo I. México: UNAM.

Alva, Bartolomé de

1634 Confesionario mayor y menor en lengua mexicana y pláticas contra las supersticiones de idolatría que el día de hoy han quedado a los naturales desta Nueva España, e instrucciones de los santos sacramentos. México: Francisco Salbago.

BARRERA, Florencio y Claudio Barrera

2009 «La falsificación de títulos a comienzos del siglo XX». Históricas 72: 41-63.

BATAlla, Juan José

1996 «Prisión y muerte de Motecuhzoma según el relato de los códices mesoamericanos». Revista Española de Antropología Americana 26: 101-120.

BERDAN, Frances F.

1994 «Economic Alternatives Under Imperial Rule: the Eastern Aztec Empire», en Economies and Polities in the Aztec Realm, Mary Hodge y Michael H. Smith, eds., pp. 291-312. Albany: Institute for Mesoamerican Studies.

BRUMFIEL, Elizabeth M.

1983 «Aztec state making: ecology, structure and the origin of the state». American Anthropologist 85: 261-284.

BRUMFIEL, Elizabeth M. y John W. Fox (eds.)

1994 Factional competition and political development in the New World. Cambridge: Cambridge University Press.

Carrasco, Pedro

1972 «La casa y la hacienda de un señor tlalhuica». Estudios de Cultura Nahuatl 10: 225-244.

Chalmers, Alan F.

1994 [1972] ¿Qué es esa cosa llamada ciencia? Madrid: Siglo XXI.

Chance, John K.

2009 «Marriage Alliances Among Colonial Mixtec Elites: the Villagómez Caciques of Acatlan-Petlalcingo». Ethnohistory 56: 91-123.

Chance, John K. y Barbara L. Stark

2007 «Estrategias empleadas en las provincias imperiales: perspectivas prehispánicas y coloniales en Mesoamérica». Revista Española de Antropología Americana 37 (2): 203-233.

CoRTÉs, Hernán

1979 Cartas de relación de la Conquista de México. Madrid: Espasa Calpe.

CuAdriello, Jaime

2004 Las glorias de la República de Tlaxcala o la conciencia como imagen sublime. México: IIE - UNAM. 
DYCKERHOFF, Ursula

1998 «Dos Títulos de tierras procedentes del pueblo de Huaquilpan, Estado de Hidalgo», en De tlacuilos y escribanos, Xavier Noguez y Stephanie Word, coords., pp. 99136. Zamora: El Colegio de Michoacán.

Fernández de ReCAS, Guillermo

1961 Cacicazgos y nobiliario indígena de la Nueva España. México: Biblioteca Nacional de México e Instituto Bibliográfico Mexicano.

García ICAzBALCETA, Joaquín

1891 Pomar y Zorita. Nueva Colección de Documentos para la Historia de México III. México: Imprenta Francisco Díaz de León.

HARVEY, Herbert H.

1991 Land and Politics in the Valley of Mexico. A Thousand Year Perspective. Albuquerque: University of New Mexico Press.

HASKETT, Robert

1990 «Indian Community Land and Municipal Income in Colonial Cuernavaca. An Investigation Through Nahuatl Documents», en The Indian Community of Colonial Mexico: Fifteen Essays on Land Tenure, Corporate Organizations, Ideology, and Village Politics, Arij Ouweneel y Simon Miller, eds., pp. 130-141. Texas: Celda.

1998 «El legendario don Toribio en los Títulos Primordiales de Cuernavaca». En De tlacuilos y escribanos, Xavier Noguez y Stephanie Word, coords., pp.137-176. Zamora: El Colegio de Michoacán.

HAssig, Ross

1985 Trade, Tribute and Transportation.The Sixteenth-Century Political Economy of the Valley of Mexico. Norman: University of Oklahoma Press.

1988 Aztec Warfare. Imperial Expansion and Political Control. Norman: University of Oklahoma Press.

1994 Mexico and the Spanish Conquest. New York: Longman.

Hicks, Fred

1994 «Alliance and Intervention in Aztec Imperial Expansion», en Factional Competition and Political Development in the New World, Elizabeth Brumfiel y John Fox, eds., pp. 111-116. Cambridge: Cambridge University Press.

Hodge, Mary G.

1991 «Land and Lordship in the Valley of Mexico: The Politics of Aztec Provincial Administration», en Land and Politics in the Valley of Mexico: A Two ThousandYear Perspective, H.R. Harvey, ed., pp. 113-139. Virginia: University New Mexico.

Hodge, Mary G. y Michael E. Smith

1994 Economies and Polities in the Aztec Realm. Albany: Institute for Mesoamerican Studies.

HoEKSTRA, Rik

1990 «A Different Way of Thinking. Contrasting Spanish and Indian Social and Economic Views in Central Mexico (1550-1600)», en The Indian Community of Colonial Mexico: Fifteen Essays on Land Tenure, Corporate Organizations, Ideology, and Village Politics, Arij Ouweneel y Simon Miller, eds., pp. 60-86. Texas: Celda. 
ISRAEL, Jonathan I.

1980 Razas, clases sociales y vida política en el México Colonial, 1610-1670. México: Fondo de Cultura Económica.

LADD, Doris

1984 La nobleza mexicana en vísperas de la Independencia, 1780-1826. México: Fondo de Cultura Económica.

LOCKHART, James y Stuart Schwarz

1992 América en la Edad Moderna. Madrid: Akal.

LOHMANN, Guillermo

1948-49 «El señorío de los Marqueses de Santiago de Oropesa en el Perú». Anuario de Historia del Derecho Español XIX: 347-458.

MADAJCZAK, Julia

2007 «Algunas notas en torno a la sucesión real en Texcoco en los años 1520-1545». Itinerarios 6: 163-174.

MARTínEZ, Hildeberto

1984 Tepeaca en el siglo XVI. Tenencia de la tierra y organización de un señorío. México: CIESAS.

Martínez Baracs, Andrea

1993 «Colonizaciones tlaxcaltecas». Historia Mexicana 170: 195-250.

2008 Un gobierno de indios: Tlaxcala, 1519-1750. México: Fondo de Cultura Económica, CIESAS, Colegio de Historia de Tlaxcala.

Martínez SaldaÑa, Tomás

2004 Anales de los pueblos de la Nueva Tlaxcala. Tlaxcala: Colegio de Historia de Tlaxcala y Gobierno del Estado de Tlaxcala.

Munch, Guido

1976 El cacicazgo de San Juan Teotihuacan durante la colonia (1521-1821). México: INAH.

Noguez, Xavier y Stephanie Wood

1998 De tlacuilos y escribanos. Zamora: El Colegio de Michoacán y El Colegio Mexiquense.

Ouweneel, Arij y Simon Miller

1990 The Indian Community of Central Mexico. Amsterdam: CEDLA.

Relación de Atlitlalaquia

1986 Relaciones geográficas del siglo XVI. Tomo 6, México tomo I. México: UNAM.

RoJAs, José Luis de

1994a «After the Conquest: Quauhtinchan and the Mexica province of Tepeacac», en Economies and Polities in the Aztec Realm, Mary Hodge y Michael H. Smith, eds., pp. 405-431. Albany: Institute for Mesoamerican Studies.

1994b De México a Granada: descendientes de Moctezuma en España. El Reino de Granada y el Nuevo Mundo II: 117-134. Granada:Asociación de Americanistas Españoles y Diputación de Granada. 
2001 «Por el humo se sabe dónde está el fuego. Evidencias de la complejidad social novohispana en el testamento de don Pedro Moctezuma (siglo XVI)». Revista de Investigaciones Jurídicas 25: 379-392.

2006 «Del dicho al hecho... Los pueblos de indios de la Nueva España y la documentación», en $V$ Jornadas Cientificas sobre documentación en Castilla e Indias en el siglo XVII, Juan Carlos Galende, editor. pp. 293-311. Madrid: Universidad Complutense.

2007 «La nobleza indígena de México ante la conquista española». Trocadero 19: 5567.

2010 Cambiar para que yo no cambie. La nobleza indígena en la Nueva España. Buenos Aires: Ed. SB.

ROMERo, $\mathrm{M}^{\mathrm{a}}$ de los Ángeles

2010 «Título de San Mateo Calpulalpan, Oaxaca. Actualidad y autenticidad de un Título Primordial». Relaciones 122: 21-54.

SANTAMARINA, Carlos

1998 «La muerte de Chimalpopoca: evidencias a favor de la tesis golpista». Estudios de Cultura Nahuatl 28: 277-316.

2002 Las fuentes aztecas como narración: la muerte de señores. Tesis de Licenciatura. Universidad Complutense de Madrid.

2005a «Memoria y olvido, ostracismo y propaganda. El imperio tepaneca en fuentes e historiografía». Revista Española de Antropología Americana 35: 117-131.

2005b «Las fuentes aztecas como narración: los casus belli». Anales del Museo de América 13: 125-138.

2005c «Legitimidad, etnicidad y política entre los aztecas». Estudios Latinoamericanos 25: 205-217.

2006 El sistema de dominación azteca: el imperio tepaneca. Madrid: Fundación Universitaria Española.

Sego, Eugene B.

1998 Aliados y adversarios: los colonos tlaxcaltecas en la frontera septentrional de Nueva España. San Luis Potosí: El Colegio de San Luis, Gobierno del Estado de Tlaxcala y Centro de Investigaciones Históricas de San Luis Potosí.

Smith, Michael E.

1986 «The role of social stratification in the Aztec Empire: a view from the provinces». American Anthropologist 88: 70-91.

SousA, Lisa y Kevin Terraciano

2003 «The «Original Conquest» of Oaxaca: Nahua and Mixtec Accounts of the Spanish Conquest». Ethnohistory 50 (2): 349-400.

Spalding, Karen

1974 De indio a campesino. Lima: Instituto de Estudios Peruanos.

VALDÉs, Carlos Manuel e Ildefonso Dávila

1987 Los tlaxcaltecas en Coahuila. San Luis Potosí - Tlaxcala: El Colegio de San Luis - Gobierno del Estado de Tlaxcala. 
Wood, Stephanie

1989 «Don Diego García de Mendoza Moctezuma. A Techialoyan mastermind». Estudios de Cultura Nahuatl 19: 245-268.

1998 «El problema de la autenticidad de los Títulos y los códices del grupo Techhialoyan», en De tlacuilos y escribanos, Xavier Noguez y Stephanie Word, coords., pp. 167-221, Zamora: El Colegio de Michoacán.

Zorita, Alonso de

1891 «Breve y sumaria relación de los señores de la Nueva España». En Pomar y Zorita. Nueva Colección de Documentos para la Historia de México, edición de Joaquín García Icazbalceta, vol. III, pp. 70-319. México: Imprenta Francisco Díaz de León. 